\title{
Reducing Incidence of Plant-Caused Congenital Deformities in Livestock by Grazing Management
}

\section{RICHARD F. KEELER}

\begin{abstract}
Highlight. Effective grazing management can reduce the incidence of plant-caused deformities in livestock. The degree of success to be expected is related to certain principles of teratology. The following factors are among those that play a role: animal genotype, nature of the teratogen, dose, and susceptible gestation period. Each plant teratogen exerts its effect by a specific mechanism, and yet widely divergent teratogens can produce similar effects. The developing conceptus is not nearly so well protected as once thought from hazardous chemical compounds in the maternal circulation. When offending teratogenic plants grow in a restricted habitat or are hazardous only at certain growth periods or when the susceptible gestation period is short, then considerable success can be expected toward reducing incidence of deformities and attendant financial loss by careful grazing management methods.
\end{abstract}

Among the many agricultural operations practiced today, few are subject to greater financial hazard than the grazing of livestock on the open range. In addition to the obvious vagaries of the market, the problems with help, and the presence of predators, grazing animals are faced with a food supply of sporadic distribution, variable nutritional value, and potential toxicity.

The potential toxicity of the forage is the primary factor under consideration in this symposium - the nature of the hazards, the plants responsible, and the management methods to reduce losses. Perhaps the most insidious of all toxicity problems produced in livestock by range plants are those in which congenitally deformed offspring are produced from dams that foraged certain plants during pregnancy. The problems are insidious because the observable effects are so much delayed from time of plant ingestion. These deformities (or teratogenic effects, as they are often called) are known to be produced by a variety of plants and believed to be produced by many others. Incidence varies from a few animals to over $30 \%$ of the entire calf or lamb crop from some herds.

Twenty years ago few ranchers thought it possible that congenital deformities in livestock could arise from any cause but genetics. Most were certain that it was the "breed" when the problem was in a neighbor's herd. Consequently, when outbreaks of deformities arose in their own herds, they were reluctant to discuss it, fearing a reflection on their own breed. However, ranchers were not alone in this misconception. Until the 1940's, people generally assumed that the

\footnotetext{
The author is with the U.S. Department of Agriculture, Science and Education Administration, Poisonous Plant Research I ahoratory, Logan, Utah 84321.

Manuscript received March 30, 1977.
}

developing mammalian conceptus was in a highly protected environment (the uterus) that was impervious to the passage of hazardous materials from the outside (Wilson 1977) and, consequently, that genetic principles governed all abnormal development (Wilson 1977).

Research during the past 30 years has shown that many factors can produce teratogenic effects in mammals; direct genetic inheritance is but one of them. Genetic inheritance, infectious diseases, radiation, nutritional deficiency or excess, various industrial chemicals, drugs, and naturally occurring compounds from food and feeds, to name some, have all been implicated as teratogenic (Shephard 1976). And so, not surprisingly, certain plants ingested by livestock during pregnancy are responsible for some of the common congenital defects seen in these livestock (Keeler 1972, 1975).

In this paper I will review why the concepti from pregnant livestock are susceptible to teratogenic plants. I will select a $\mathrm{fcw}$ of the plants now known to be important as teratogenic hazards in livestock, and will discuss what is known about the epidemiology, the teratogenic compounds, the nature of the deformities, and factors that influence incidence of the deformities under natural conditions. For each example, I will then show how grazing management methods can be used to reduce incidence of the various deformities, but how the success of these methods depends upon many factors.

\section{Why is the Conceptus from Livestock Susceptible to Teratogenic Plants?}

The developing conceptus is subject to teratogenic insult, including that from poisonous plants, for many reasons. Teratogens ingested by the dam are not all immediately detoxified or excreted. Some pass the placental barrier more readily than once thought and thus enter the blood circulation of the developing conceptus. When a teratogen damages in utero a few cells of the conceptus destined to form a limb or other readily recognized part of the animal, that part does not form properly, and a grossly recognized congenital deformity results. Similarly, cells that were destined to become any tissue or organ or part thereof may be damaged and a more subtle, yet significant, deformity results.

But many, criteria must be met before a teratogen will produce a congenital defect. The criteria stem from certain biological factors that govern development of a conceptus. To explain how these factors relate to production of congenital defects, Wilson (1977) has described in detail what he calls Six Principles of Teratology. Reflection on these principles suggests why there is much variability in 
the teratogenic effects in livestock produced by poisonous plants. Let us now consider what these principles are and how they relate to livestock deformities.

\section{Principle \#1. Conceptus genotype determines susceptibility to a teratogen.}

Genetic inheritance is not solely responsible for the defect as was once believed. Rather, teratogen susceptibility varies among genotypes. Not only is there variation among species in susceptibility, but there is also variation among strains or breeds as well. Although almost no research exists on this subject among livestock breeds, the very extensive differences found among laboratory animal strains (Schardein 1976) leave little doubt that variation would be expected in livestock. Thus, teratogenic plants could be the cause of epidemics of deformities in livestock even though incidence and deformity type varied from ranch to ranch among animals grazing the same ranges.

\section{Principle \#2. The teratogen must reach the conceptus or produce an influence that does.}

As mentioned above, the placenta is not as extensive a barrier as once thought. In fact "virtually all unbound chemicals in maternal plasma have access to the conceptus across the placenta" (Wilson 1977). Thus, the important consideration is whether they reach the conceptus at a dose that will give rise to the effect. The importance of dose leads to a consideration of principle \#3. Furthermore, the importance of dose suggests there may be a very large number of potential teratogenic plants from among the many hundreds that livestock encounter. Teratogenic plants could go unrecognized until epidemics occurred.

Principle \#3. The deformity produced is dose dependent.

Thus, although all chemicals of the plasma have access to the conceptus, the important consideration is the question of dose. Does sufficient teratogen reach the conceptus to produce the effect? Factors that govern conceptus-dose in our consideration of plant teratogens and livestock follow. Enough of the plant must be eaten, the teratogen must be liberated therefrom, enough teratogen must survive degradation in the rumen and elsewhere in the gut, must then be absorbed into the maternal circulation, must survive metabolism in the dam, must pass the placenta, must reach the circulation of the conceptus, and finally must reach the site of insult at the susceptible gestational period. Thus, the extent of deformity is dependent on many factors that combine to influence the amount that reaches the conceptus when it is susceptible. Translated to livestock operations, the greater the amount of teratogenic plant eaten and the higher the teratogen concentration in the plant the higher the incidence and greater the extent or severity of the deformity expected, provided the teratogen survives intact enroute to the conceptus.

\section{Principle \#4. A teratogen can produce death rather than deformity.}

Teratogens are toxic in a wider sense than the name implies. “. . . (Teratogens) capable of causing any adverse biologic effect can usually also be shown to be embryotoxic under the right conditions of dose, developmental stage, and species susceptibility unless maternal toxicity intercedes"
(Wilson 1977). Thus, at high doses many teratogens kill either the conceptus or the dam. So in livestock, a high incidence of abortions or resorptions (seen as a poor lamb or calf crop) may accompany or signal a problem with plant teratogens.

\section{Principle \#5. The conceptus must be exposed at the susceptible period.}

During development of a conceptus, events are specific and rigidly controlled. Organs and tissues begin to form at specific times; cells destined to divide to give rise to recognizable anatomical features appear at specific moments. Thus, if a teratogen is to produce a specific deformity, it must exert its influence at exactly the right time in gestation. In Table 1 the timing for expected deformities (the insult periods) are compared during embryonic and fetal development for 5 mammals (man, hamsters, sheep, cattle, and pigs). Insult time among the species listed varies remarkably. This variation stems in part from the great differences in total gestation time and the consequent time variation in gestational events. Thus, the primitive streak/ neural plate stages of embryonic development, at which time embryos may develop cyclopia if insulted by a teratogen, occur at about day 7 in the hamster but not until day 14 in sheep. Consequently, in a given class of livestock, we would expect that a particular type of deformity would be produced only as a consequence of maternal ingestion of a plant at a specific gestation period and that the period would not necessarily be the same for each class of livestock.

Table 1. Approximate gestation day when teratogens produce defects in five mammalian species.*

\begin{tabular}{|c|c|c|c|c|c|}
\hline \multirow{2}{*}{ Defect } & \multicolumn{5}{|c|}{ Gestation days when teratogens produce defects in } \\
\hline & Man & Hamsters & Sheep & Cattle & Pigs \\
\hline Micropthalmia & $16-17$ & 6.5 & $12-13$ & $16-18$ & $10-11$ \\
\hline Cyclopia & $21-23$ & 7.0 & 14 & 21 & 12 \\
\hline $\begin{array}{l}\text { Exencephaly } \\
\text { (anencephaly) }\end{array}$ & 26 & 7.5 & 16.5 & $26-27$ & 15.5 \\
\hline $\begin{array}{l}\text { Spina bifida } \\
\text { (meningomyelocele) }\end{array}$ & $28-29$ & $8-8.5$ & 18 & $29-31$ & 17 \\
\hline Shortened limbs & 36 & 9.5 & $29-31$ & 42 & 20 \\
\hline $\begin{array}{l}\text { Total gestation } \\
\text { time (days) }\end{array}$ & 267 & 16 & 147 & 283 & 115 \\
\hline
\end{tabular}

*Adapted from Winters et al. 1942; Green and Winters 1945; Witschi 1956; Shenefelt 1972; and Schardein 1976.

\section{Principle \#6. Each teratogen exerts its effect by a specific} mechanism.

If a conceptus is to be adversely affected by a teratogen, events must be occurring in the conceptus that can be influenced by the specific mechanism that teratogen influences. But many dissimilar teratogens may influence the same mechanism and thereby give rise to similar deformities. Thus, in livestock, one can expect first, that the type of deformity expressed would be greatly dependent upon whether specific events were occurring in the conceptus (would be dependent upon the time of gestation), and second, that similar deformities in neighboring herds might not necessarily be caused by the same plant (or the same teratogen). 


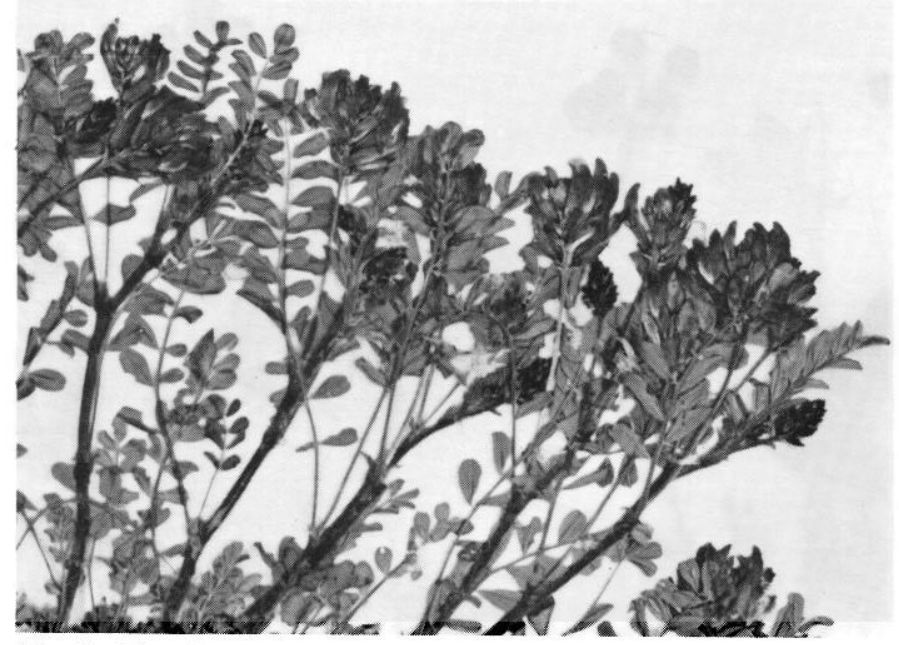

Fig. 1. The plant species Astragalus lentiginosus.

\section{Plants That Cause Deformities in Livestock, Their Teratogens, Types of Deformities Produced, and Grazing Management Methods Available to Reduce Incidence}

Many range plants are known to be teratogens and many others are suspected teratogens (Keeler 1972, 1975). In this section, I have selected for consideration six plants for which rather solid evidence exists that they do produce deformities in livestock. They will be considered in depth as examples of how grazing management methods can sometimes, but not always, be used to reduce incidence when information related to the six principles of teratology is available.

\section{Loco Plants}

Some of the loco plants, for example spotted loco (Astragalus lentiginosus Dougl.) (Fig. 1) and greenriver milkvetch (Astragalus pubentissimus Torr. \& Gray), cause, in addition to classical locoism, deformities and abortions in offspring from dams that ingested these plants during gestation (James et al. 1967). Deformed lambs (Fig. 2) have

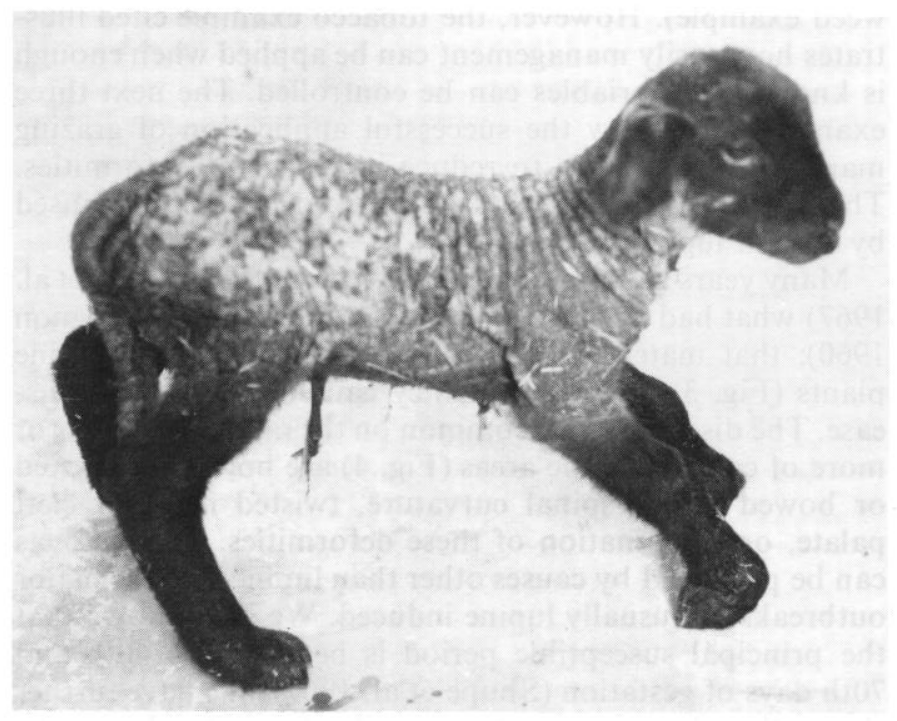

Fig. 2. Deformed lamb from material ingestion of Astragalus during gestation. excessive flexure of the carpal joints or tendon contracture, or both, and may have anterior flexure and hypermobility of the hock joints (James et al. 1967). The susceptibility period of the conceptus is very broad. Deformities of one type or another occur under natural and experimental conditions at almost any period of gestation (James et al. 1969). Experimental production of the deformities has shown that the plant is indeed the cause. Incidence on the range is highly sporadic, primarily because of the variable abundance of the plant. But in years of heavy plant abundance, incidence of abortions may approach $60 \%$, and up to $30 \%$ or more of the live lambs dropped may be deformed (James et al. 1967). Identity of the teratogenic compound is unknown. Seeds of some of these teratogenic loco plants are viable in soil for protracted periods, perhaps more than 50 years, and plant abundance evidently is governed by the amount of moisture available to initiate germination and early growth and by subsequent seedling competition. Removal of juniper (Juniperus spp.) and sagebrush (Artemisia spp.) by chaining in some areas has increased loco abundance. But unless moisture conditions remain favorable, plant abundance declines.

Available grazing management methods to reduce deformities and abortions caused by loco are limited. Because animals are susceptible at all gestation stages, no "safe" grazing period can be found; therefore, one could probably not exploit information on teratogen content as a function of growth stage of the plant in order to reduce the dose were it known. One cannot effectively reduce dose by assuring adequate amounts of other feed because animals become addicted to the loco and seek it to the exclusion of other plants. Attempts at careful herding in loco-infested areas have not been an adequate means of reducing loco intake. Thus, the only successful grazing management method to reduce incidence of deformities and abortion from loco (and indeed incidence of classical locoism as well) has been to remove animals from loco-infested ranges, rest the range, and hope for a better year next year - or suffer the loss. Thus, with loco-induced deformities, understanding the 6 principles of teratology described above and how they relate to the problem does not result in a practical solution. On the basis of information provided, we have seen why the principles cannot be successfully exploited with loco.

\section{Tobacco Plants}

A unique, interesting teratogenic effect occurs in offspring from sows that grazed tobacco stalks (Nicotiana tabacum L.) during gestation. In some midwestern tobaccoraising areas, farmers allow pigs to graze the tobacco stalks that remain in the field after the leaves have been removed for curing. Crowe (1969) observed that more than 300 pigs from 64 litters on 5 Kentucky farms were born with skeletal defects. The sows had access to tobacco stalks during pregnancy, and he speculated that the stalks were responsible for the deformities. Menges et al. (1969) reported on a similar tobacco-related epidemic of congenital deformities of swine. Twisting of the fore or hind limbs and dorsal flexure of the hind limb digits were common. Breeding records ruled out genetics as the cause. Crowe and Pike (1973), who reported observation on over 1,000 malformed newborn pigs, suggested that if tobacco were the cause, then the susceptible period was between days 10 and 30. Crowe and Swerczek (1974) were able to produce the effect by feeding tobacco 
stalks or tobacco leaf filtrates. Thus, the plant is responsible, but the active principle remains unknown. However, one of the toxic pyridine alkaloids common to the plant may be responsible for the deformities.

Adequate grazing management methods are available to eliminate this problem. Because sows are susceptible only until day 30 of gestation, one can keep them from pastures containing tobacco stalks until all have passed day 30 . Alternatively, supplemental feeding might reduce intake of the stalks enough to drop the dose to the conceptus to a level below which deformities are produced. I cite this example to illustrate the ease with which one can solve plant-induced deformity problems when one understands the 6 principles mentioned above and when one has complete control of the factors. I cite it also to illustrate that a problem in one species of animals and one species of plants can alert us to other potential problems.

Many plants of the Nicotiana and other genera found commonly on western ranges contain pyridine alkaloids. If one or more of the pyridine alkaloids prove to be teratogenic, then these plants may pose a problem for grazing livestock and may account for some of the deformities observed in these areas. But these areas are usually grazed by sheep and cows - not pigs, and thus the conceptus may not be of a susceptible genotype. We are now investigating those matters.

\section{Jimsonweed and Related Plants}

Leopold, et al. (1973) speculated that an outbreak of twisted limbs in pigs resulted from maternal ingestion of jimsonweed (Datura stramonium L.) during the 2 nd and 3 rd months of pregnancy. Twisted limbs occurred in 25 offspring from 8 litters of newborn pigs. The sows had farrowed in a drylot that was surrounded by a dense stand of jimsonweed. The sows had shown typical signs of jimsonweed intoxication including incoordination. On subsequent investigation it was obvious that the plant had been foraged. Jimsonweed seemed the most likely cause since the authors were able to rule out a genetic cause.

If one can show by feeding trials that the plant is indeed responsible, then a number of related plants may come under suspicion. A known toxic class of compounds in jimsonweed, and known to be responsible for clinical poisoning signs, is the tropane alkaloid class (Keeler 1975). That class would be among the prime possibilities from which the teratogen will be found. In addition to jimsonweed, other range plants are high in tropane alkaloids, such as deadly nightshade (Atropa belladonna L.) and henbane (Hyocyamus niger L.) (Keeler 1975).

Knowing the six principles of teratology, we can see that it is too early to devise a grazing management strategy to eliminate deformities allegedly caused by jimsonweed. What information do we lack? First, we must show by feeding trials that the plant does cause deformities in pigs. We must know the gestational insult period. We must determine whether other classes of livestock are susceptible. We must know when the plant is most teratogenic, either by feeding trials or by determining the active principle and how it varies. This example illustrates the process we must go through from the time any plant first comes under suspicion as being one that produces deformities until we are finally able to devise a grazing strategy.

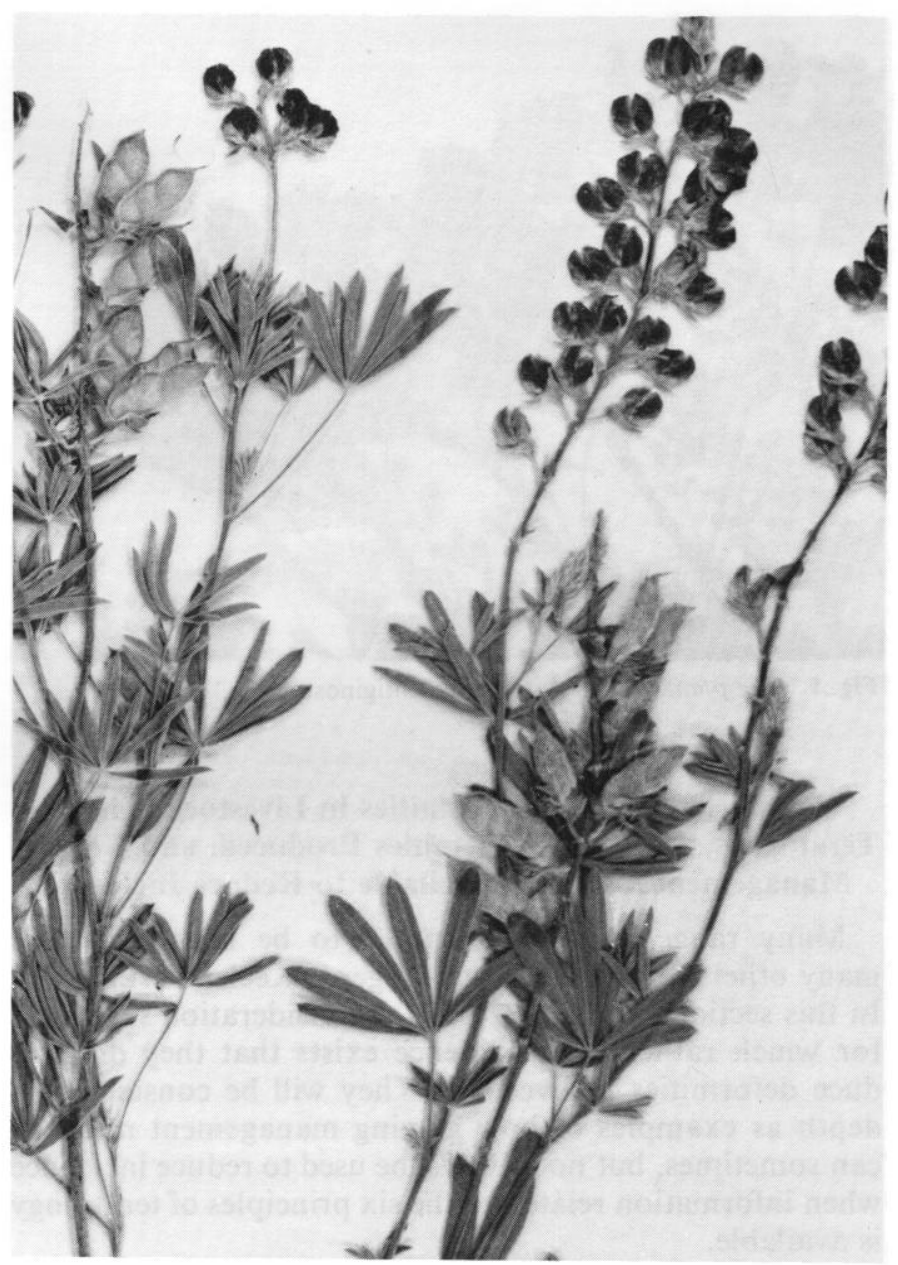

Fig. 3. The plant species Lupinus sericeus.

\section{Lupine Plants}

The three examples already cited have shown some of the problems in using grazing management methods to reduce incidence of plant-caused deformities - because of the magnitude of the problem (the loco plant example) or because of the lack of sufficient information (the jimsonweed example). However, the tobacco example cited illustrates how easily management can be applied when enough is known and variables can be controlled. The next three examples will show the successful application of grazing management methods to reduce incidence of deformities. The first of the three deals with crooked calf disease caused by certain lupine plants.

Many years ago, we showed by feeding trials (Shupe et al. 1967) what had been earlier speculated by others (Wagnon 1960): that maternal ingestion by cows of certain lupine plants (Fig. 3) during pregnancy caused crooked calf disease. The disease is very common on the range; up to $30 \%$ or more of calves in some areas (Fig. 4) are born with twisted or bowed limbs, spinal curvature, twisted neck, or cleft palate, or combination of these deformities. These effects can be produced by causes other than lupine, but the major outbreaks are usually lupine induced. We have shown that the principal susceptible period is between the 40th and 70th days of gestation (Shupe et al. 1967). We have further shown that the compound responsible from the plant is the quinolizidine alkaloid anagyrine (Keeler 1973, 1976). From 


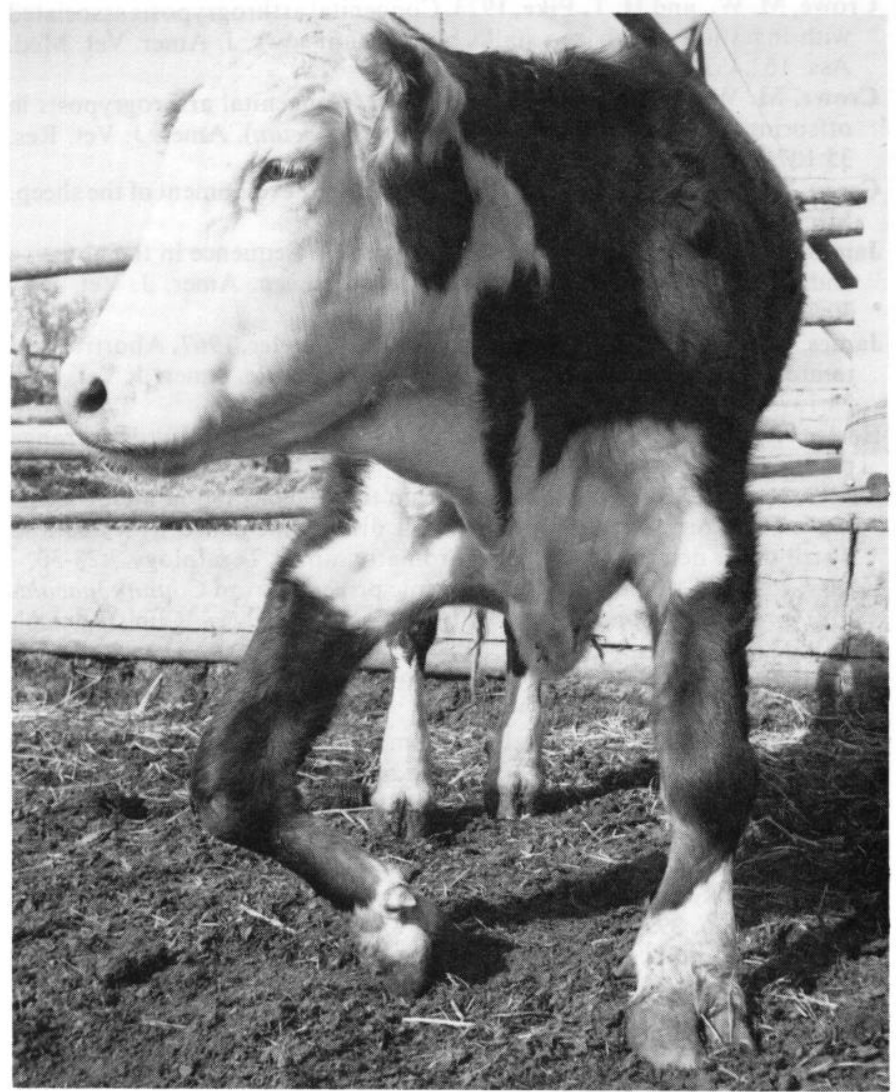

Fig. 4. Deformed calf from material ingestion of Lupinus during gestation.

among the many hundreds of lupines, we know of at least four that contain this teratogenic compound - Lupinus sericeus Pursh., Lupinus caudatus Kell., Lupinus laxiflorus Dougl., and one unidentified species from Alaska. Surely there are others.

Exploiting information about the susceptible gestational period by changing breeding times has reduced incidence during the past few years by those willing to change breeding times. But we believed that if plant concentration of anagyrine varied as a function of plant maturity, then that, too, might be exploited to reduce incidence by finding periods when the plant was safe to graze. Thus, to reduce incidence, a rancher could prevent cows from grazing lupine if anagyrine content were high and the cows were in the susceptible period. The alternative of herding animals away from the plant on the range is not very practical because of the rather uniform distribution of the plant.

We measured anagyrine content in $L$. sericeus and $L$. caudatus as a function of plant maturity. Concentration was high, so plants were very teratogenic in early growth, but their teratogenicity decreased markedly with maturity. But there was also a high concentration for a brief period while mature seeds remained in the pods (Keeler et al., 1976).

So the best strategy to reduce incidence of crooked calf disease produced by $L$. sericeus or $L$. caudatus relates to susceptible gestational period and teratogen concentration in the plant (Keeler et al., 1977). We take advantage of some of those six principles of teratology and reduce the dose during the critical period, knowing that this reduced dose will reduce incidence. Teratogenicity is maximum when young plants or plants in mature seed stage are grazed by cows whose average gestation stage is between the 40th and 70th days. Teratogenicity is minimum when lupine of either early flower or post-seed stage is grazed by cows whose average stage of gestation is either earlier than the 40th or later than the 70th day.

We have examined ranch records dating back as far as 25 years from six ranches where the disease has been a problem. Incidence varied from year to year but was related to gestation time and anagyrine content in the plants and was unrelated to various supplementation practices (Keeler et al. 1977). So for this deformity, grazing managment coupled with breeding changes allows a reduction of incidence and represents the only viable alternative at present.

\section{Poison Hemlock}

Poison hemlock (Conium maculatum L.) produces in calves certain congenital deformities that are similar to those produced by lupine (Keeler 1974; Keeler and Balls 1978). But the problem is minor compared with the lupine problem because poison hemlock is less abundant and less palatable than lupine. For these reasons, fewer animals eat the plant; and when they do, they eat less.

Clinically, one cannot distinguish the hemlock-induced condition from the lupine-induced; twisted limbs and spinal curvature are the typical signs. The insult period also is in the 40-70th day gestation range (Keeler, 1974). The teratogenic compounds in the plant are simple piperidine alkaloids (Keeler 1974; Keeler and Balls 1978) and concentration of these alkaloids in the plant is highly variable. So there is little hope to lower dose by selective grazing during a low hazard period. Fortunately, the plant usually grows in restricted areas, mainly along fences, in waste places, and in over-grazed pastures.

Management strategy to reduce incidence is based on lowering the dose. Animals must be kept from these plants or the plants must be controlled by cutting, cultivation, herbicide treatment, or pasture improvement. These techniques have been successfully used by some ranchers.

\section{Veratrum Plants}

The final example of the use of grazing management to reduce plant-caused congenital deformities is the most impressive. It is impressive because the susceptible gestation period is so short and because of the very restrictive habitat of the plant. Both of these have combined to make elimination of the condition possible using management tools

Many years ago, epidemics of cyclopia and related facial deformities occurred in newborn lambs in some parts of Idaho (Binns et al. 1960; Binns et al. 1963). Occasionally, incidence exceeded $25 \%$ in lambs from individual ranches. The deformed offspring were single- or double-globe cyclopics usually with a proboscis above the eye (Fig. 5), or in cases of lesser severity the lower jaw appeared pronounced and curved up around a very much shortened upper jaw (Binns et al., 1960). Feeding trials at our laboratory established that false hellebore (Veratrum californicum Durand) was responsible for the condition (Binns et al. 1963) when it was ingested by the pregnant ewe on the 14th day of gestation (Binns et al. 1965). The plant propagates by rhizome and grows in dense, sharply defined stands in high moist meadow or side-hill sites.

We have determined that the teratogenic compound in 


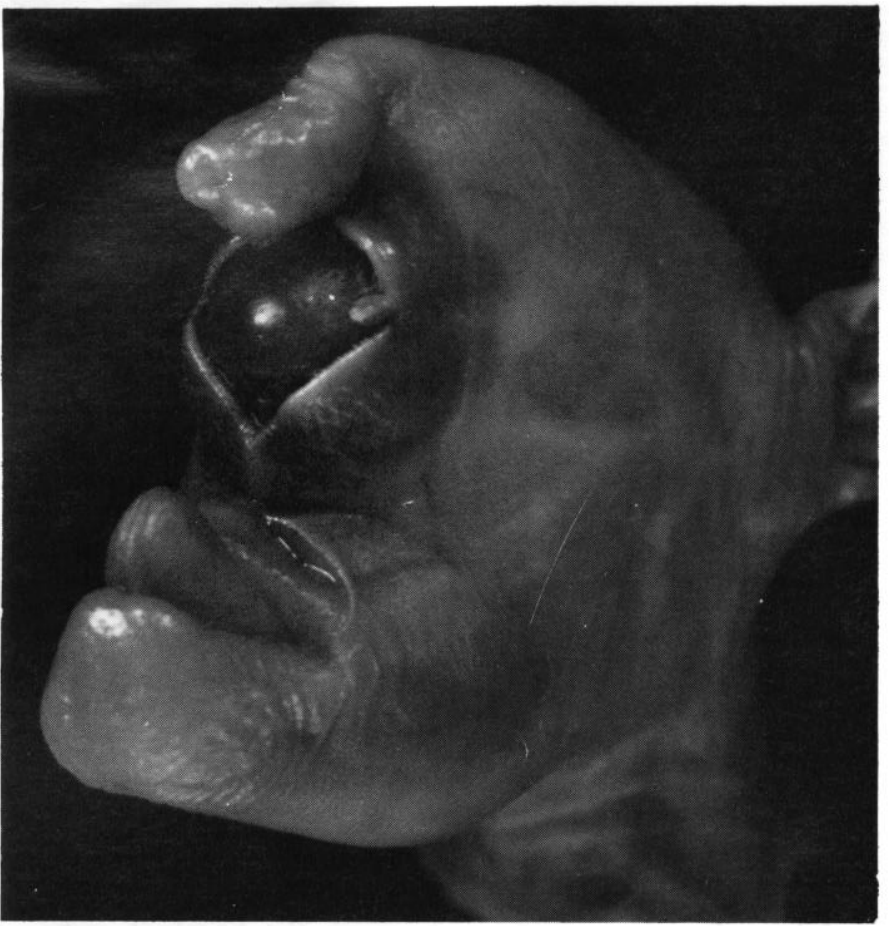

Fig. 5. Cyclopic lamb from material ingestion of Veratrum during gestation.

the plant is cyclopamine, a steroidal alkaloid (Keeler and Binns 1968). Our experimental work has revealed considerable information about the structural features necessary to confer teratogenicity on the molecule (Keeler 1978). We have concerned ourselves with teratogenicity/structure aspects because of widespread presence in other foods and feeds of compounds that are structurally related to cyclopamine. We have also determined that the concentration of cyclopamine in above-ground, or foraged, parts of the plant decreases as the plant matures during the summer.

But from a grazing management point of view, information about the chemistry of the teratogen is unnecessary. We need only to know: (a) that the plant is responsible, (b) that the insult to the conceptus occurs on the 14th day, and (c) that the plant grows in sharply defined stands in a restrictive habitat. Ranchers now successfully exploit these facts to reduce incidence by preventing ewes from grazing this plant until the rams have been removed for at least 15 days. They keep the ewes in areas where the plant does not grow until all ewes have passed the susceptible period.

\section{Literature Cited}

Binns, W., W. A. Anderson, and D. J. Sullivan. 1960. Cyclopian-type malformation. J. Amer. Vet. Med. Ass. 9:515-521.

Binns, W., L. F. James, J. L. Shupe, and G. Everett. 1963. A congenital cyclopian-type malformation in lambs induced by maternal ingestion of a range plant, Veratrum californicum. Amer. J. Vet. Res. 24:1164-1175.

Binns, W., J. L. Shupe, R. F. Keeler, and L. F. James. 1965. Chronologic evaluation of teratogenicity in sheep fed Veratrum californicum. J. Amer. Vet. Med. Ass. 147:839-842.

Crowe, M. W. 1969. Skeletal anomalies in pigs associated with tobacco. Mod. Vet. Pract. 50:54.
Crowe, M. W., and H. T. Pike. 1973. Congenital arthrogryposis associated with ingestion of tobacco stalks by pregnant sows. J. Amer. Vet. Med. Ass. 162:453-455.

Crowe, M. W., and T. W. Swerczek. 1974. Congenital arthrogryposis in offspring of sows fed tobacco (Nicotiana tabacum). Amer. J. Vet. Res. 35:1071-1073.

Green, W. W., and L. M. Winters. 1945. Prenatal development of the sheep. Minnesota Tech. Bull. \#169.

James, L. F., R. F. Keeler, and W. Binns. 1969. Sequence in the abortive and teratogenic effects of locoweed fed to sheep. Amer. J. Vet. Res. 30:377-380.

James, L. F., J. L. Shupe, W. Binns, and R. F. Keeler. 1967. Abortive and teratogenic effects of locoweed on sheep and cattle. Amer. J. Vet. Res. 28:1379-1388.

Keeler, R. F. 1972. Known and suspected teratogenic hazards in range plants. Clin. Toxicol. 5:529-565

Keeler, R. F. 1973. Lupin alkaloids from teratogenic and nonteratogenic lupins. I. Correlation of crooked calf disease incidence with alkaloid distribution determined by gas chromatography. Teratology 7:23-30.

Keeler, R. F. 1974. Coniine, a teratogenic principle from Conium maculatum producing congenital malformations in calves. Clin. Toxicol. 7:195-206.

Keeler, R. F. 1975. Toxins and teratogens of higher plants. Lloydia 38:56-86.

Keeler, R. F. 1976. Lupin alkaloids from teratogenic and nonteratogenic lupins. III. Identification of anagyrine as the probable teratogen by feeding trials. J. Toxicol. Environ. Health 1:887-898.

Keeler, R. F. 1978. Alkaloid teratogens from Lupinus, Conium, Veratrum, and related genera. In: Effects of Poisonous Plants on Livestock, R. F. Keeler, K. R. Van Kampen, and L. F. James (eds.), Academic Press, New York, p. 397-408.

Keeler, R. F., and L. D. Balls. 1978. Teratogenic effects in cattle of Conium maculatum and conium alkaloids and analogs. Clin. Toxicol. (In Press).

Keeler, R. F., And W. Binns. 1968. Teratogenic compounds of Veratrum californicum (Durand). V. Comparison of cyclopian effects of steroidal alkaloids from the plant and structurally related compounds from other sources. Teratology 1:5-10.

Keeler, R. F., E. H. Cronin, and J. L. Shupe. 1976. Lupin alkaloids from teratogenic and nonteratogenic lupins. IV. Concentration of total alkaloids, individual major alkaloids, and the teratogen anagyrine as a function of plant part and stage of growth and their relationship to crooked calf disease. J. Toxicol. Environ. Health. 1:899-908.

Keeler, R. F., L. F. James, J. L. Shupe, and K. R. Van Kampen. 1977. Lupine-induced crooked calf disease and a management method to reduce incidence. J. Range Manage. 30:97-102.

Leipold, H. W., F. W. Oehme, and J. E. Cook. 1973. Congenital arthrogryposis associated with ingestion of jimsonweed by pregnant sows. J. Amer. Vet. Med. Ass. 162:1059-1060.

Menges, R. W., L. A. Selby, C. J. Marienfeld, W. A. Aue, and D. L. Greer 1969. A tobacco related epidemic of congenital limb deformities in swine. Environ. Res. 3:285-302.

Schardein, J. L. 1976. Drugs as Teratogens. CRC Press, Inc. Cleveland p. 9-25.

Shenefelt, R. E. 1972. Morphogenesis of malformations in hamsters caused by retinoic acid: Relation to dose and stage of treatment. Teratology 5:103-118.

Shepard, T. H. 1976. Catalog of teratogenic agents. Second Edition Johns Hopkins Press, Baltimore, Endpaper section.

Shupe, J. L., W. Binns, L. F. James, and R. F. Keeler. 1967. Lupine, a cause of crooked calf disease. J. Amer. Vet. Med. Ass. 151:198-203.

Wagnon, K. A. 1960. Lupine poisoning as a possible factor in congenital deformities in cattle. J. Range Manage. 13:89-91.

Wilson, J. G. 1977. Current status of teratology - General principles and mechanisms derived from animal studies. In: Handbook of Teratology. J. G. Wilson and F. C. Fraser (eds.), Vol. 1 Plenum Press, New York p. 47.

Winters, L. M., W. W. Green, and R. E. Comstock. 1942. Prenatal development of the bovine. Minnesota Tech. Bull. \#151.

Witschi, E. 1956. Development of Vertebrates. W. B. Saunders Co., Philadelphia. p. 405 